\title{
Jogos e brincadeiras na educação infantil como resgate da identidade cultural na infância
}

Games and play in child education as a clearence of cultural identity in the infance

Poliana Bernabé Leonardeli Marcilene Conti Valeria Barbosa

Resumo: A pesquisa busca demonstrar como o ato de brincar pode ser importante na vida da criança, influenciando-a na percepção do mundo real, no desenvolvimento da psicomotricidade e na criatividade, contribuindo no processo de ensino aprendizagem durante a Educação Infantil. O trabalho ressalta que as brincadeiras fazem parte do dia a dia dos alunos e são uma forma de linguagem que contribui para o desenvolvimento cognitivo, além do desenvolvimento nos aspectos da criatividade e imaginação infantis. O professor pode estabelecer a importância do seu papel nesse processo, fazendo com que a criança possa construir e reconstruir relações sociais, históricas, artísticas e culturais, uma vez que a primeira atividade social da criança ocorre pela brincadeira. A pesquisa procura ainda demonstrar a importância da memória e do resgate das brincadeiras e jogos tradicionais como forma de construção de uma identidade cultural. Busca também evidenciar como essas brincadeiras tão antigas podem desenvolver uma série de habilidades previstas na BNCC para educação infantil. A metodologia utilizada é a pesquisa de campo, com o objetivo de verificar como é a percepção e o trabalho dos professores com as brincadeiras na Educação Infantil no cotidiano da sala de aula.

Palavras-chave: Brincadeiras. Educação Infantil. Games. Professor.

\begin{abstract}
This research aims to demonstrate how the act of playing can be important in the child's life and how it can influence the perception of the real world, the development of psychomotricity and creativity, contributing to the process of teaching learning in early childhood education. This research emphasizes that play is part of children's daily life, and a form of language, which contributes to their cognitive development, in addition to development in the aspects of creativity and imagination, where the teacher can establish the importance of its role in this process, enabling the child to build and rebuild social, historical, artistic and cultural relationships, and the child's first social activity is through play. And show the importance of memory and rescue of traditional games. The methodology used is the field research, with the objective of verifying how is the perception and the work of the teachers with the games in the kindergarten.
\end{abstract}

Keywords: Play. Early Childhood Education. Games. Play Teacher. 


\section{Introdução}

A finalidade do trabalho é demonstrar a relevância das brincadeiras e jogos tradicionais no processo de ensino e aprendizagem na Educação Infantil, pois, ao serem utilizadas como recurso pedagógico, contribuem para o desenvolvimento cognitivo das crianças, uma vez que estimulam a criatividade e a imaginação, bem como servem como meio de resgate da memória e a da Cultura Popular, propiciando a crianças ainda muito pequenas contato com a identidade coletiva.

O professor, nesse sentido, atua para efetivar o brincar como meio de ensino e aprendizagem, fazendo com que a criança crie autonomia através de brincadeiras, e prepare-se para construir e reconstruir socialmente relações interacionais, históricas, artísticas e culturais, pois ao brincar a criança adquire conhecimentos que contribuem para a construção de uma identidade. $\mathrm{O}$ ato de brincar pode ser, nesse sentido, importante, por influenciar na percepção do mundo real e também no desenvolvimento da psicomotricidade e da criatividade.

Portanto, o trabalho busca relacionar teorias acerca dos benefícios que a brincadeira proporciona ao desenvolvimento infantil e também analisar se na instituição escolar onde a pesquisa foi aplicada, os docentes inserem em seus planejamentos trabalhos pedagógicos com as brincadeiras tradicionais, estimulando as crianças a conhecê-las e, ainda, identificar se aproveitam delas para o desenvolvimento geral do educando, segundo previsto na BNCC para a Educação Infantil.

Pretende-se chegar à compreensão de como o ato de brincar na sala de aula pode se tornar significativo e possibilitar a interação social e o conhecimento do mundo ao educando, uma vez que a criança, quando brinca, expressa o que está sentindo e o faz por meio de uma linguagem não verbal ou imaginária mais afeita a elas nessa idade. Isso faz com que demonstrem tudo aquilo que, às vezes, não podem ou não sabem explicar em linguagem referencial.

Para a criança, brincadeira e realidade misturam-se. Os momentos que envolvem ludicidade são de extrema importância para o amadurecimento infantil, 
e para o adulto esses momentos são importantes para que possam, como citado, compreender melhor o que se passa no interior dessa criança.

A partir dessa perspectiva, o trabalho será desenvolvido em tópicos, organizados de modo a atingir a resposta que almejamos. A primeira parte debruça-se sobre a metodologia da pesquisa, procurando também fundamentação do ponto de vista teórico, por meio de opiniões de especialistas e trabalhos recentes publicados na área. Como principais estudiosos do assunto, utilizamos as publicações de autores renomados como Piaget, Vigotsky, Freire, Kishimoto, Maluf e Moyles, dentre outros. Buscaremos também referências nos documentos oficiais que agem como norteadores do processo de ensino da Educação Infantil, como os DCNs, RNCEls e BNCC.

Logo após, busca-se estabelecer a relação das brincadeiras tradicionais com a memória coletiva, e conduzir a reflexão acerca do uso de brincadeiras antigas e tradicionais, que continuam vivas nas lembranças de alguns adultos, porém, nem sempre são inseridas no contexto escolar, o que as leva ao esquecimento. Considera-se isso muito grave, uma vez que o fato representa uma quebra de identidade entre gerações com impacto no contexto cultural da sociedade. Nisso reside a importância da discussão.

$\mathrm{Na}$ seção seguinte, procura-se abordar os benefícios pedagógicos da brincadeira em todos os seus aspectos, incluindo-se o desenvolvimento psicomotor, cognitivo, comunicativo. Destaca-se que o ensino de excelência na Educação Infantil possui ligação intrínseca com o uso de brincadeiras durante as situações de aprendizagem.

A última seção trará o resultado da pesquisa de campo, desenvolvida em uma escola pública de Educação Infantil no Município de Linhares - ES. Dessa forma, poderemos compreender como ocorre o uso da prática de brincadeira nesse espaço. Além disso, faremos algumas reflexões a fim de concluir melhor nossa pesquisa.

\section{Aportes teóricos}

A criança precisa sentir-se estimulada para buscar o saber, e nada mais interessante que este ocorrer pelas brincadeiras. A leitura, logo que se iniciou o 
trabalho e escolheu-se o tema, apontou para vários teóricos que defendem aplicação do lúdico na Educação Infantil, sendo eles: Maluf (2003), Moyles (2002), kishimoto (2003), Piaget (1978), Friedman (1996), Weiss (1993), entre outros. Por meio da exploração da produção acadêmica desses autores foi elaborado um texto inicial com o objetivo de demonstrar que existem inúmeras teorias e pesquisas que comprovam a eficácia das brincadeiras no desenvolvimento infantil, bem como esclarecer que esse é um direito das crianças presente na lei 8.069, de 13 de julho de 1990, Estatuto da Criança e do Adolescente (ECA), capítulo II, artigo $16^{\circ}$, inciso IV, que estabelece o direito de "brincar, praticar esportes e divertir-se".

Além de ser um direito garantido por lei, segundo a nova Base Nacional Comum Curricular (BNCC), o uso das brincadeiras no processo de ensino é um elemento indispensável à formação do educando, pois visam o desenvolvimento geral de competências cognitivas, culturais, criativas e comunicativas.

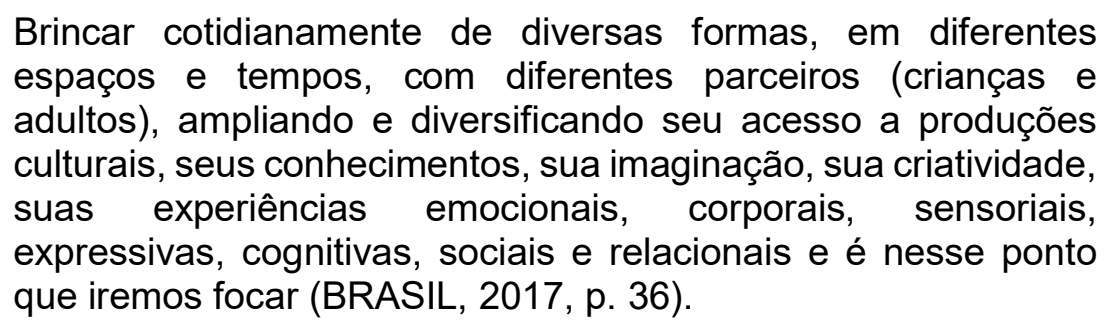

Segundo Maluf (2003), quando a criança brinca, independentemente da idade e da classe social sentirá prazer naquele momento, pois é livre para fazer o que sente vontade e é neste momento feliz da criança que haverá um maior aprendizado, ou seja, ela estará aberta a absorver tudo o que o brincar lhe possa oferecer, porque se sente envolvida e vivencia situações do cotidiano.

Ao brincar, as crianças se assumem nessas brincadeiras e permitem-se expressar e experimentar diferentes sensações, favorecendo seu lado de desenvolvimento emocional e afetivo. Por isso, diz-nos Maluf (2003, p. 17): "O verbo brincar nos acompanha diariamente. Brincar sempre foi e sempre será uma atividade espontânea e muito prazerosa, acessível a todo o ser humano, de qualquer faixa etária, classe social ou condição econômica”.

Neste sentido, ao brincar a criança constrói sua personalidade, pois está se sentindo à vontade, expressando o que sente e o que pensa sem mascarar o 
que na realidade ela é e, ao mesmo tempo, proporcionando se conhecer, ou seja, naquele instante entende suas preferências e suas rejeições, porque quando brinca, rejeitará colegas, brinquedos e tudo o que não lhe agrada e, ao mesmo tempo, aceitará tudo o que Ihe agrada. De acordo com Maluf (2003, p. 12):

Poderiam também compreender o objetivo do brincar, percebendo como ele se manifesta nas diversas faixas etárias, a partir das contribuições teóricas e do ponto de vista conceitual, histórico-cultural e educativo, como recurso de construção da identidade de cada ser humano, de autoconhecimento e como elementos potencializados do trabalho educativo.

A criança precisa sentir-se estimulada para querer buscar o saber e nada mais interessante que este vir em forma lúdica, tornando o aprendizado satisfatório, pois a criança tornar-se-á mais interessada em conhecer algo que Ihe pareça prazeroso e se empenhará sempre em aprender mais e mais (MOYLES, 2002).

Além disso, a cada aprendizado a criança se sentirá melhor, elevando sua autoestima, pois entenderá que tem capacidade de aprender, e quando sente que é capaz tudo é feito com mais envolvimento e empolgação. Nesse sentido, Maluf diz que:

A busca do saber torna-se importante e prazerosa quando a criança aprende brincando. É possível, através do brincar, formar indivíduos com autonomia, motivados para muitos interesses e capazes de aprender rapidamente (2003, p. 9).

É brincando que a criança experimenta situações de emoções da vida adulta e, assim, assimila o que está ao seu redor, proporcionando o conhecimento sobre o mundo. Por exemplo, quando a criança brinca de ser mãe ou pai, ele tentará a ter atitudes próprias de seus pais com gestos e movimentos que cabem aos adultos. Por isso, nos lembra Kishimoto (2003, p. 81):

Toda e qualquer brincadeira exige regras, mesma que estas não sejam explicitas, como e o caso do faz de conta. Pelo fato de estar interagindo com outras pessoas e com a realidade social com um todo, a criança observa condutas, apropria-se de valores e significados, compondo um repertório de regras que tecem os diversos papéis sociais. É assim que traz para a situação imaginária, suscitada pela brincadeira, regras de comportamento. 
As brincadeiras influenciam no desenvolvimento das crianças, incentivando-as e estimulando-as em várias atividades sejam elas físicas, mentais ou afetivas. A criança, quando está brincando, percebe tudo o que está à sua volta: objetos, pessoas, natureza e a importância de cada um deles (MOYLES, 2002).

Quando brinca, a criança cria e recria ao mesmo tempo, imagina situações do dia a dia, cria novas situações, exercita a mente, pois algumas brincadeiras precisam ter o raciocínio rápido para que possam ser realizadas. De acordo com Maluf (2003, p. 77):

Nunca devemos esquecer que brincar é altamente importante na vida da criança, primeiro por ser uma atividade na qual ela já se interessa naturalmente e, segundo, porque desenvolvem suas percepções, sua inteligência, suas tendências à experimentação.

Portanto, brincar de uma forma direcionada ao objetivo pedagógico, com materiais selecionados e que vão provocar algum tipo de desenvolvimento da criança, seja motor, físico, intelectual, despertando-lhes a curiosidade e a criatividade provoca, de acordo com a maior parte dos pesquisadores explorados, o desenvolvimento integral da criança (WEISS, 1993). Para isso, o professor deve conhecer cada aluno e cada habilidade a ser desenvolvida por ele, para que possa escolher as brincadeiras e atividades específicas.

Enquanto brinca, a criança imagina, inventa, reinventa, interage com o mundo e com o outro, conhecendo a si e ao mundo que a rodeia. A brincadeira desenvolve a motricidade da criança, promove processos de socialização e descoberta do mundo, bem como os sentimentos, as emoções e as atitudes irão fluir naturalmente (WEISS, 1993). Da mesma forma, vemos no Referencial Comum Curricular Nacional da Educação Infantil (BRASIL, 1998, v. 1, p. 28):

Pela oportunidade de vivenciar brincadeiras imaginativas e criadas por elas mesmas, as crianças podem acionar seus pensamentos para a resolução de problemas que lhes são importantes e significativos. Propiciando a brincadeira, portanto, cria-se um espaço no qual as crianças podem experimentar o mundo e internalizar uma compreensão particular sobre as pessoas, os sentimentos e os diversos conhecimentos. 
Ou seja, quando a criança brinca experimenta o mundo à sua volta, percebe suas limitações, sente-se livre, diverte-se, aprende aquilo que ainda não sabe com muito prazer e alegria. Assim, "em todas as idades, o brincar é realizado por puro prazer e diversão e cria uma atitude alegre em relação à vida e à aprendizagem. Isso certamente é uma razão suficiente para valorizar o brincar" (MOYLES, 2002, p. 21).

É importante ressaltar que ao brincar a criança desenvolve sua autoestima e, consequentemente, a confiança, melhorando o seu relacionamento com o outro, o que propicia uma melhor interação com aqueles à sua volta. Quando a criança está envolvida numa brincadeira, ela se envolve também com as pessoas que estão ao seu redor, podendo aumentar a sua afetividade, sentir a importância que o outro tem e criar laços de amizade (MALUF, 2003).

Portanto, os momentos em que as crianças estão brincando são os melhores para investir-se na construção de relações com as pessoas ou outras crianças em volta, como diz Maluf (2003, p. 94): "É através das brincadeiras que a criança faz novas amizades, melhora seu relacionamento com seus pais, educadores e entre colegas em um ambiente lúdico, tranquilo". Ou seja, ao brincar a criança aprende espontaneamente a tomar decisões e construir sua identidade, pois a partir daí ela conhecerá o que ela gosta e o que não gosta, conforme vemos no manual de orientação pedagógica (BRASIL, 2012, p. 7):

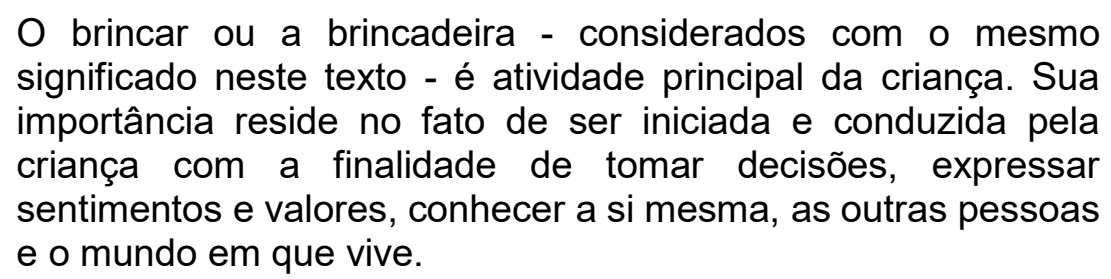

No momento das brincadeiras, a criança desperta a curiosidade, demonstra satisfação no que faz e, por conseguinte, desenvolve-se como um todo, melhorando o seu relacionamento com o outro, desenvolvendo 0 pensamento, a habilidade psicomotora e expressando melhor os afetos e emoções.

As brincadeiras têm vários benefícios, dentre os quais se destacam: o desenvolvimento da força, equilíbrio, agilidade, concentração, coordenação 
motora, força muscular, espírito de equipe e habilidade para lidar com regras e disputa. Segundo Maluf (2003, p. 19) "[...] brincar [...] desenvolve os músculos, a mente a sociabilidade, a coordenação motora e além de tudo deixa qualquer criança feliz". Dessa forma, a criança desenvolve seu lado intelectual e físico, pois os movimentos das brincadeiras auxiliam a manter um corpo saudável, trazendo benefícios para o corpo e a mente.

Portanto, para a Educação Infantil se efetivar é preciso que existam momentos de prazer e descontração e isso pode ser desenvolvido através das brincadeiras desafiadoras e significativas, que facilitam a construção do aprendizado de forma agradável e descontraída. De acordo com Maluf (2003, p. 30), "pode-se afirmar que o brincar, enquanto promotor da capacidade e potencialidade da criança, deve ocupar um lugar especial na prática pedagógica, tendo como espaço privilegiado a sala de aula".

Pelo brincar a criança pode se desenvolver de diversas maneiras, pois tem a liberdade de tomar decisões, conhecer o mundo, a si e quem está a sua volta. A esse respeito, Friedmann (1996, p. 25) nos mostra que "podemos considerar o brincar como uma linguagem, através da qual as crianças se comunicam, entre si e com os adultos". Então, pode-se perceber que o brincar proporciona diversos saberes às crianças. Cabe aos educadores compreender essa importância e se beneficiar dela.

\section{Brincadeiras e Memória Coletiva}

A sociedade atual, pautada nos valores capitalistas, levou à desagregação de hábitos e costumes de gerações anteriores. A rápida urbanização e o advento dos meios tecnológicos consumidos por todas as classes afastaram as crianças dos espaços sociais e das brincadeiras tradicionalmente desenvolvidas em coletividade, as chamadas brincadeiras tradicionais ou populares.

Essas brincadeiras que, paulatinamente são substituídas por aparatos eletrônicos: tablets, celulares, games, cumprem uma função interacional que não ocorre por meio de jogos modernos e ainda resgatam a cultura do ato de brincar, evidenciando sua importância no processo de desenvolvimento das crianças, 
uma vez que por meio das brincadeiras populares a criança aprende junto ao convívio familiar e da comunidade, num contexto que permite a troca de experiência e interioriza os valores e costumes herdados dos antepassados, em um processo de construção de uma identidade cultural (HUIZINGA, 2000).

Segundo Vygotsky (apud Oliveira 1997), o método de desenvolvimento do ser humano marca-se por sua inserção num determinado grupo cultural, "de fora para dentro", pela qual o indivíduo realiza as suas ações externas, que serão interpretadas pelas pessoas que fazem parte do seu do seu grupo social, na escola, em casa e na comunidade.

As Diretrizes Curriculares Nacionais da Educação Infantil, em seu artigo $4^{\circ}$, definem a criança como:

Sujeito histórico e de direitos, que, nas interações, relações e cotidianas que vivência, constrói sua identidade pessoal e coletiva, brinca, imagina, fantasia, deseja, aprende, observa, experimenta, narra, questiona e constrói sentimentos sobre a natureza e a sociedade, produzindo cultura (BRASIL, 2009).

Dessa forma, o resgate das brincadeiras tradicionais no ensino da Educação Infantil coopera para que a criança perceba e valorize sua cultura e seu contexto social, e que ela não fique perdida no contexto social, mas que contribua para sua formação e amplie seu universo cultural, além de ser um instrumento de enorme potencial educativo, que possibilita aos alunos um saber popular, e leva-os a descobrir regras básicas, relacionadas ao meio em que vivem (HIUZINGA, 2000).

Como mostra Oliveira (1997, p. 35) para Vygotsky no "[...] decorrer do seu processo de desenvolvimento, a criança deixa marcas externas e passa a usar signos internos, isto é uma imagem mental que substitui os objetivos do mundo real". É pelas brincadeiras que a criança explora o meio onde vive, aprendendo mais sobre objetos e culturas. Ela, ao brincar, significa a brincadeira, de acordo com sua vivência e cultura.

Existe uma diversidade de brincadeiras tradicionais que são benéficas em diversas áreas: motoras, cognitivas, afetivas, sociais, além de servirem, como aqui se evidenciou, como instrumentos de resgate cultural. As referidas brincadeiras resistem ao tempo e continuam contribuindo para o 
desenvolvimento das crianças, independentemente da cultura em que estas estão inseridas.

Porém, a vida urbana e a ocupação dos progenitores das crianças no mundo do trabalho, agem, muitas vezes, como impedimento no uso dessas brincadeiras em ambiente familiar. A escola pode resolver essa fratura, aplicando essas brincadeiras nos espaços pedagógicos.

As brincadeiras tradicionais podem ser inseridas como um recurso precioso no processo de ensino. Algumas podem ser adaptadas aos conteúdos do Currículo Programático, pois são muito importantes para o desenvolvimento físico, motor, social e cultural das crianças e precisam ser conhecidas por elas, desde brincadeiras tradicionais acumuladas desde a antiguidade até outras ligadas à nossa cultura (VELASCO, 1996).

Silva (1989) destaca que, através de algumas brincadeiras, a criança aprende a conhecer culturas diferentes, originadas na antiguidade por pessoas de várias religiões, classes sociais e etnias. De acordo com o autor:

As brincadeiras são, então, um meio para se chegar ao coletivo geral da humanidade; nelas a criança trabalha questões importantes da essência do ser humano: medo, fantasias, fazde-conta, além de experimentar relações sociais presentes em determinado coletivo (grupo social a que pertence), como cooperação, competição, ganhar, perder, comandar, subordinarse etc (SILVA, 1989, p. 75).

Essas brincadeiras tradicionais que vêm dos antepassados podem ser chamadas de patrimônio, pois se constituem de experiências e costumes dos povos da antiguidade e são transmitidas de pai para filho conforme as tradições, apesar de terem sofrido modificações com o passar dos anos. De acordo com PELEGRINI e FUNARI (2008, p. 62):

[...] esse patrimônio se constitui de um conjunto de formas de cultura tradicional e popular ou folclórica, ou seja, as 'obras coletivas' queemanam de uma cultura e se fundamentam nas tradições transmitidas oralmente ou a partir de expressões gestuais que podem sofrer modificações no decorrer do tempo por meio de processos de recriação coletiva.

Entende-se, então que, com a passagem do tempo, algumas brincadeiras não desapareceram, mas sofrem transformações e adaptações, demonstrando 
que são perenes. Por isso, devem ser passadas de geração a geração, para que não se percam as lembranças das brincadeiras de pais, avós e tios. Faz-se, assim, um resgate também de valores coletivos.

Percebe-se que as brincadeiras antigas, também conhecidas como populares ou tradicionais, fazem parte da cultura popular, e que muitas destas atividades lúdicas continuam sendo desenvolvidas na sua forma inicial, outras foram adaptadas e sofreram evoluções com o passar do tempo, mas continuam com uma importância significativa para a evolução e desenvolvimento das crianças que Ihes permite a criação de autonomia, o desenvolvimento da criatividade, a aptidão para a resolução de conflitos e vários outros benefícios para desenvolvimento de competências na Educação Infantil. De acordo Com Oliveira (2000, p. 160):

Por meio da brincadeira, a criança pequena exercita capacidades nascentes, como as de representar o mundo e de distinguir entre pessoas, possibilitadas especialmente pelos jogos de faz-de-conta e os de alternância respectivamente. Ao brincar, a criança passa a compreender as características dos objetos, seu funcionamento, os elementos da natureza e os acontecimentos sociais. Ao mesmo tempo, ao tomar o papel do outro na brincadeira, começa a perceber as diferenças perspectivas de uma situação, o que lhe facilita a elaboração do diálogo interior característicos de seu pensamento verbal.

As brincadeiras tradicionais tornam-se grandes aliadas e oportunizam inúmeras aprendizagens no processo de construção cognitiva do aluno, já que possibilitam ao educando descobrir, inventar e aprender. As brincadeiras populares são uma atividade socioeducativa fundamental na interação entre o grupo e na construção de conhecimentos da realidade cultural, pois constituem divertimento e contribuem no processo de aprendizado ao estimular atitudes de sociabilidade, vivência em um mundo imaginário, autonomia e introjetar, com isso, valores culturais nas novas gerações (WESS, 1993).

\section{Brincadeiras tradicionais e desenvolvimento cognitivo}

A Educação Infantil é, muitas vezes, a primeira circunstância real de separação da criança do seu espaço familiar, o que Ihes oportuniza socializar com outras pessoas e crianças, de diferentes culturas e contextos sociais. A 
Base Nacional Comum Curricular diz em sua proposta sobre Educação Infantil, que são "seis os direitos de aprendizagem e desenvolvimento que asseguram a aprendizagem da criança na Educação Infantil, colocando-as em situações que possam desempenhar um papel ativo em ambientes desafiadores, onde são convocadas a resolvê-los" (BRASIL, 2017, p. 37, 38). Esses espaços são: "conviver, brincar, participar, explorar, expressar e conhecer-se".

Além desses campos de experiências, que constituem um arranjo curricular que acolhe as situações e as experiências concretas da vida cotidiana das crianças e seus saberes, a Base (BRASIL, 2017, p. 40, 41, 42 e 43) procurou organizá-las de modo mais específico nos eixos: "o eu, o outro e o nós”, "corpo, gestos e movimentos", "traços, sons, cores e formas", "escuta, fala, pensamento e imaginação", "espaços, tempos, quantidades, relações e transformações", numa intenção de possibilitar que as crianças "ampliem seus conhecimentos do mundo físico e sociocultural e possam utilizá-los em seu cotidiano".

O Currículo do Espírito Santo, que tem sido adotado pelas escolas públicas de Linhares segue a BNCC no que concerne aos textos dedicados ao trabalho com a Educação Infantil. O documento preparado pelo estado segue os seguintes objetivos a serem explorados no processo de ensino.

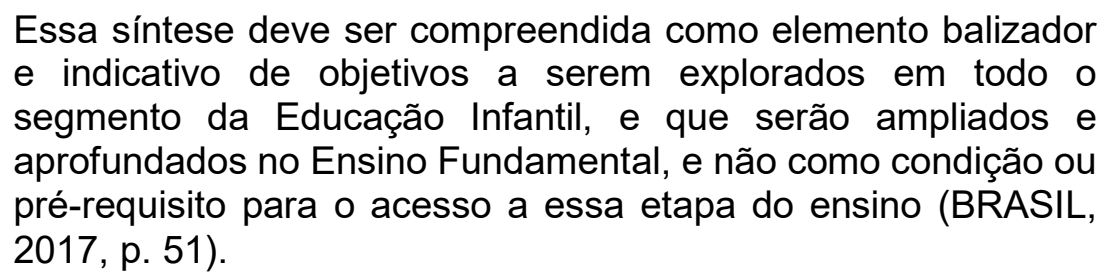

Vejamos, a seguir, em que consistiu a pesquisa que dá fundamento a este texto.

Materiais e métodos

Tendo em vista a importância de utilizar as brincadeiras na prática pedagógica, e seu valor no desenvolvimento cognitivo e social na Educação Infantil, realizou-se uma pesquisa de campo para um melhor embasamento das considerações feitas.

No que se refere à pesquisa de campo, Gil (2008) diz que este recurso procura o aprofundamento de uma realidade específica. Ela desenvolve-se como 
meio da observação direta dos procedimentos do grupo estudado e de entrevistas com os sujeitos inseridos em determinada circunstâncias, buscando esclarecimentos e explanações.

A entrevista que fornece as fontes para a execução da pesquisa foi realizada com professores da rede de Ensino Municipal de Linhares. A instituição escolhida foi o CEIM José Cândido Durão, que fica localizada na Avenida João Bonicenha, quadra $36, \mathrm{~S} / \mathrm{N}^{\circ}$, bairro São José. A escola funciona nos dois turnos e possui 30 (trinta) professores, com a carga horário de 4 (quatro) horas/aula dia, 5 (cinco) monitoras de Educação Infantil, 5 (cinco) estagiárias (remuneradas), para atender 328 (trezentos e vinte e oito) alunos que são, em grande maioria, pertencentes a classe social média e baixa.

A escola não possui espaços adaptados para crianças com necessidades especiais, como previsto legalmente, por isso tem previsão de reformas no ano de 2020, a fim de que se adapte um banheiro a esses alunos, construam-se rampas para acessos a demais ambientes da escola, bem como reformas nos demais banheiros e pintura em todo o CEIM.

A pesquisa de campo foi realizada com 8 (oito) professoras efetivas da escola, uma vez que as outras docentes, alegando diversas situações, não aceitaram participar da pesquisa. A idade média das docentes que participaram variou de 35 a 45 anos, todas são formadas em Pedagogia, e possuem especializações em áreas como: Educação Especial Inclusiva, Educação Infantil e Gestão Escolar. O tempo de experiência profissional médio delas é de cerca de 10 anos.

A pesquisa teve como objetivo verificar, através de um questionário, se os professores utilizam brincadeiras, incluindo as tradicionais, em sua prática pedagógica, e se costumam adequá-las ao planejamento cotidiano, aproveitando-se delas para os desenvolvimentos de competências e habilidades descritas na BNCC. Quanto à técnica do questionário Gil (1999, p. 128) nos diz que:

O questionário consiste em um procedimento de investigação composta por um número mais ou menos elevado de questões apresentados por escrito às pessoas, tendo por objetivo o 
conhecimento e opiniões, crenças, sentimentos, interesses, expectativas, situações vivenciadas.

O questionário destinado às professoras da Educação Infantil compôs-se de 7 (sete) perguntas, que seguem anexadas ao final da pesquisa. Ao longo da análise, procurar-se-á citá-las indiretamente e comentá-las à luz do que foi pesquisado e apreendido: a importância da brincadeira no processo de ensino aprendizado da criança, e sua grande contribuição, não só como diversão, mas como algo que enriquece a prática pedagógica de forma integra, conforme lembra Maluf (2003), ao afirmar que a brincadeira não pode ser encarada somente como uma diversão, mas como a primeira etapa educacional, pelas próprias características da idade da criança, pelo gosto, pelo prazer e pelo aprendizado, promovendo assim uma preparação para a vida.

\section{Análise dos resultados}

O primeiro questionamento aplicado aos envolvidos na pesquisa buscou compreender qual a rotina das brincadeiras no cotidiano pratico das professoras. Todas as entrevistadas afirmam usar as brincadeiras em seu cotidiano, e entendem a importância do uso delas em seu dia a dia. Uma delas disse: "a criança aprende muito através das brincadeiras, principalmente as regras, combinados e o respeito com os colegas e professores". Outra professora completa, afirmando: "o uso das brincadeiras enriquece minhas práticas pedagógicas". Conforme o RCNEI (BRASIL, 1998, p. 105) "é o adulto, na figura do professor, portanto, que na instituição infantil, ajuda a estruturar o campo das brincadeiras na vida das crianças". Sendo assim, o professor deve organizar espaços e tempo para brincar, por meio de objetos, fantasias, brinquedos, jogos e brincadeiras, oferecendo materiais adequados e participando desses momentos lúdicos, o que contribui para o enriquecimento da brincadeira como atividade social do universo infantil. Quanto a isso, todos os professores parecem cumprir a função de adotar as brincadeiras na rotina escolar.

A segunda questão buscou compreender qual o tempo dedicado a essas brincadeiras na rotina. Houve divergências nessas respostas, pois algumas 
professoras responderam que seguem uma rotina diária, e que utilizam "30 a 40 minutos para as brincadeiras livres e dirigidas", e uma professora disse que "não tem um tempo específico dedicado para a brincadeira, vai depender muito da rotina e o objetivo a ser alcançado".

A resposta da grande maioria deixou implícita a informação de que a brincadeira não está inserida na rotina pedagógica, ou seja, ela tem apenas um fim em si mesmo. Ao contrário, uma única docente demonstrou entender o uso da brincadeira como processo, de acordo com a visão de teóricos especialistas na área e do que prevê os documentos referenciais da Educação Infantil: "O educador deveria desempenhar um papel fundamental como mediador das brincadeiras infantis, mas com um olhar voltado ao aprendizado do aluno" (MOYLES, 2002, p. 118).

A terceira pergunta buscou evidenciar quais brincadeiras são utilizadas em sala e se são tradicionais, bem como o que essas atividades poderiam desenvolver no educando. As professoras citaram várias: faz de conta, dança da cadeira, amarelinha, telefone sem fio, batata que passa-passa, coelhinho sai da toca, pula corda, pique pega, pique se esconde, morto vivo, chicotinho queimado, senhor caçador, cantigas de roda, adivinhações, além de jogos atuais, como boliche, bingo e jogos de bolas. Demonstraram repertorio bem diverso e com profunda riqueza cultural, mas não evidenciaram objetivos claros na execução de nenhuma delas, faltando-Ihes repertorio teórico e objetivos específicos para seu uso no ambiente escolar.

As brincadeiras tradicionais oportunizam às crianças experimentar diversas experiências pois, por meio delas, desempenham diversos papéis, cuja formação, com o tempo, contribuirá para torná-las sujeitos críticos, reflexivos, atuantes e ativos. Em vista disso, seguimos para a quarta pergunta que buscou saber se essas brincadeiras possuem regras claras e se possibilitariam a construção de estratégias de convivência: A maioria das professoras afirmou que sim, duas professoras se aprofundaram mais, afirmando que "as brincadeiras de faz de conta não possuem regras, mas as brincadeiras com regras são utilizadas, pois ajudam no desenvolvimento social da criança"; outra disse que "sim, pois são primordiais para o convívio em grupo". 
As brincadeiras antigas possibilitam o contato com a cultura infantil do passado como também o desenvolvimento da criança em aspectos cognitivos gerais. Nesse sentido, a quinta pergunta relaciona-se à posterior, uma vez que se complementam e procuram evidências de que o professor entende a importância do resgate das brincadeiras tradicionais como meio de construção de uma Identidade cultural no alunado. As respostas foram as mais diversas. Todas afirmaram usar as brincadeiras antigas, e citaram as brincadeiras de amarelinha, pular corda, morto vivo, pique pega, cantigas de roda, batata quente, bambolê, cabo de guerra, caça tesouro, chicotinho queimado e telefone sem fio mas, quando indagados do poder da memória e do sentido patrimonial disso em sala, foram incapazes de desenvolver as questões.

Já sabendo dos objetivos a serem traçados quando uma aula em Educação Infantil é planejada, partimos para a sétima pergunta que foi: Quais seus objetivos para o ensino ao utilizar brincadeira no cotidiano de seus alunos? De modo geral, as participantes da pesquisa não se aprofundaram, mas responderam de formas diferentes, como: "a brincadeira é essencial para o desenvolvimento, pois através delas posso observar como as crianças estão e o que eles já dão conta e o que precisa ser trabalhado"; a segunda professora disse que "o que eu percebo através de cada brincadeira, o lúdico nos auxilia a alcançar os objetivos traçados em cada atividade proposta, refletindo positivamente na aprendizagem de cada criança", e uma terceira professora respondeu que as brincadeiras tradicionais "possibilitam o desenvolvimento psicomotor da criança em relação à criatividade, à lateralidade, à criação de novas estratégias e o cumprimento de regras e limites.

Acerca dos objetivos, as professoras citaram diversos, dentre eles: "que a criança amplie suas habilidades motoras e cognitivas, e aprenda a respeitar os combinados e regras, respeitando os colegas e o professor"; "desenvolver o raciocínio, aprender a conviver com o outro, despertar o gosto do aprender através das brincadeiras", e ainda que "é a partir da interação e do convívio com outras crianças que ela começa a construir sua identidade e a descobrir o outro".

Diante do exposto, percebe-se que as professores da Educação Infantil da escola investigada utilizam as brincadeiras em seu cotidiano e reconhecem a 
sua importância no dia a dia do aluno, porém, eles optam para uma aprendizagem formal, e deixam de lado o espaço da brincadeira, mesmo sabendo que é o momento mais importante da vida da criança, quando ela aprende com prazer, e é capaz de descobrir seu papel dentro do grupo social, além de experimentar novas habilidades e seus limites. Outra situação percebida é a de que as brincadeiras tradicionais não são exploradas em toda sua abrangência, sejam nas suas funções de desenvolvimento do cognitivo, na estimulação a imaginação e nos resgates reais da memória e identidade.

\section{Conclusões}

A discussão sobre a importância da brincadeira no contexto escolar é muito ampla e muitos professores já se conscientizaram de que a brincadeira contribui positivamente para o desenvolvimento das crianças em seus aspectos cognitivos, sociais, físicos e afetivos.

Desse modo, entende-se que o ambiente das escolas de Educação Infantil deve ser estimulante, seguro e acessível para promover o desenvolvimento das crianças. O espaço tem que ser lúdico, dinâmico, vivo, para que a criança possa aprender brincando. Vale lembrar que para possuir um espaço assim, o educador também deve possuir essas qualidades.

A criança aprende melhor brincando e todos os conteúdos podem ser ensinados através de brincadeiras, pois não existe nada que a criança precisa aprender que não possa aprender brincando. Para tanto, é preciso que em sua prática pedagógica o professor possibilite a seus alunos materiais convenientes.

A brincadeira, na busca de novos conhecimentos, exige do educador uma postura inovadora, reflexiva e criativa; pois educar ludicamente não é jogar lições prontas para o educando consumir passivamente. Educar deve ser um ato consciente e planejado, é tornar o indivíduo consciente, engajado e feliz.

Através das brincadeiras na Educação Infantil estimulam-se as crianças a fantasiar, cooperar, obedecer a regras, a se organizar em equipe e outros, portanto, estimular as crianças a imaginar, criar, envolver-se já é um grande passo para um aprendizado significativo, pois os jogos, brinquedos e 
brincadeiras na infância são meios mais eficientes de enriquecimento e desenvolvimento da personalidade.

As atividades lúdicas e brincadeiras auxiliam as crianças a desenvolverem habilidades sociais e de conhecimento, bem como contribuem na formação do educando que, ao socializar, amplia seu repertório linguístico, aprende a trabalhar em equipe e aprende melhor e de maneira significativa os conteúdos propostos. Além disso, visa contribuir na formação integral do educando, estimulando valores como: autoestima, inclusão, coletividade, igualdade de direitos, deveres e desenvolvimento humano.

Ao trabalhar as brincadeiras, o educador tem a possibilidade de compartilhar, unir os alunos para que possa interagir, socializar e participar das atividades propostas, além de incentivar o aluno a assumir riscos, reforçando a confiança pessoal e interpessoal.

Portanto, ao trabalhar com brincadeiras populares o professor deve buscar estratégias de acordo com o nível de aprendizado dos educandos, para que possam desenvolver gradativamente seu aprendizado, pois essas atividades, além de serem lúdicas, exercem um papel fundamental na formação dos educandos, sendo possível reunir dentro da mesma situação o lúdico e o educar.

Portanto, a importância das brincadeiras tradicionais, ou quaisquer outras, na Educação Infantil possibilita a assimilação de conhecimento, levando a criança a vivenciar situações concretas de resolução de problemas, conforme percebida em nossa pesquisa com as docentes de um Centro de educação infantil municipal. Quando a criança está inserida no processo, permite-se o aprendizado dos conceitos de uma maneira geral, desenvolvendo as habilidades cognitivas e motoras.

Enfim, a educação lúdica integra, na sua essência, uma concepção teórica profunda e uma prática atuante e concreta que ainda precisam ser compreendidas e aplicadas com mais afinco pelos educadores. 


\section{Referências}

BONTEMPO, Edda. A brincadeira de faz-de-conta: lugar do simbolismo, da representação, do imaginário. In: KISHIMOTO, T.M. (orgs). Jogo, Brinquedo, Brincadeira e a Educação. 5.ed. São Paulo. Cortez, 2001.

BRASIL. Ministério da educação e do Desporto. Secretaria de Educação Fundamental. Referencial Curricular Nacional para a Educação Infantil. v. 1. Brasília; MEC/SEF, 1998.

. Ministério da educação. Base Nacional Comum Curricular - BNCC Versão final. Brasília, DF, 2017.

. Ministério da Educação. Secretaria de Educação Básica. Brinquedos, brincadeiras e materiais para bebês: manual de orientação pedagógica: módulo 2. Brasília: MEC/SEB, 2012.

. Ministério da Educação. Secretaria de Educação Básica. Brinquedos, brincadeiras e materiais para crianças pequenas: manual de orientação pedagógica: módulo 3. Brasília: MEC/SEB, 2012.

. Ministério da Educação. Secretaria de Educação Básica. Brinquedos

e Brincadeiras Nas Creches. Brasília: MEC/SEB, 2012.

CASCUDO, Luís da Câmara. Dicionário do folclore brasileiro. $10^{\circ}$. ed. SP: Editora Global, 2001.

FREIRE, Paulo. Pedagogia da autonomia. São Paulo: Paz e terra, 2006.

FRIEDMANN, Adriana. Brincar: crescer e aprender o resgate do jogo infantil. São Paulo: Moderna, 1996.

GIL, Antônio Carlos. Métodos e técnicas de pesquisa social. 5. Ed. São Paulo: Atlas, 1999.

HUIZINGA, Johan. Homo ludens: O jogo como elemento da cultura. São Paulo: Perspectiva, 2000.

KISHIMOTO, Tizuko Morchida. Jogo, brinquedo, brincadeira e a educação. São Paulo: Cortez, 2004.

MALUF, Angela Cristina Munhoz. Brincar: prazer e aprendizado. Petrópolis: Vozes, 2003.

MOYLES, Janet R. Só brincar? O papel do brincar na educação Infantil. Porto Alegre: Artmed, 2002.

OLIVEIRA, Marta Kohl de. Vygotsky: aprendizado e desenvolvimento um processo sócio histórico. São Paulo: Scipione, 1997.

PELEGRINI, Sandra; FUNARI, Pedro Paulo. O que é Patrimônio Cultural Imaterial. São Paulo: Brasiliense, 2008.

PIAGET, Jean. A psicologia da criança. Rio de janeiro: Bertrand Brasil, 1976. A psicologia da criança. Rio de Janeiro: Bertrand Brasil, 1978. 
SILVA, Maria Alice Setúbal Souza e. Memória e brincadeiras na cidade de São Paulo nas primeiras décadas do século XX. São Paulo: Cortez, 1989.

SMOLE, K. S.; DINIZ, M. I. S. V.; CÂNDIDO, P T. Brincadeiras infantis nas aulas de matemática. Porto Alegre, Artmed, 2010.

VELASCO, Casilda Gonçalves. Brincar. O despertar psicomotor. Rio de Janeiro: Sprint, 1996.

WEISS, Louise. Brinquedos \& Engenhocas. 2. ed. São Paulo: Scipione, 1993.

\section{Sobre os autores}

\section{Poliana Bernabé Leonardelli}

Email: pleonardeli@gmail.com

Doutoranda em Letras (UFES). Mestra em Letras (UFES). Professora adjunta de Língua Portuguesa na Faceli, Linhares, ES.

\section{Marcilene Conti}

Email: marcilene conti@live.com

Graduada em Pedagogia (Faceli). Professora de Educação Infantil da rede municipal de Linhares, ES.

\section{Valéria Barbosa dos Santos}

Email: vdgotas@gmail.com

Graduada em Pedagogia (Faceli). Professora de Educação Infantil da rede municipal de Linhares, ES. 


\section{CURSO DE LICENCIATURA EM PEDAGOGIA}

Questionário destinado aos professores da Educação Infantil para coleta de dados para pesquisa de campo

1. Você insere brincadeiras na sua rotina de trabalho no espaço escolar?

2. Qual a frequência reservada para as brincadeiras em sua rotina?

3. Que tipos de brincadeiras chamam mais a atenção das crianças na sala da aula?

4. A brincadeiras utilizadas possuem regras?

5. Você costuma resgatar brincadeiras antigas e trazê-las para a sala? Se sim, cite algumas.

6. As brincadeiras que você insere em sala desenvolvem o cognitivo dos alunos? Explique 